ISSN: 2386-9658

\title{
Ortografía a través de los dictados: propuesta didáctica para italófonos
}

\section{(Orthography through dictation: didactic proposal for italophones)}

\author{
RuBÉN GONZÁLEZ VALLEJO \\ u156528@usal.es \\ Universidad de Salamanca
}

Fecha de recepción: 24 de abril de 2019

Fecha de aceptación: 30 de diciembre de 2019

Resumen: Si bien los manuales de español se centran en ejercicios de comprensión oral de elección múltiple o de cloze, es innegable el beneficio de trabajar con dictados de diversa índole en el aula, ya que facilita la adquisición de estructuras semánticas de la lengua en el discente a la vez que este realiza una identificación de las palabras para su posterior transcripción revisando la ortografía. El presente trabajo toma como referencia la premisa de que los dictados pueden ser un gran aliado para la adquisición de la ortografía y se centra principalmente en una propuesta didáctica basada en una cohorte de dictados para un alumnado de origen italiano de nivel C1-C2 que engloba las convenciones ortográficas más importantes recogidas en la Ortografía de la lengua española de la RAE y en el Plan Curricular del Instituto Cervantes. El posterior trabajo del error y de la ortografía comparada del español y el italiano constituirán el segundo objetivo de este estudio.

Palabras clave: Ortografía. Dictado. Interlengua. Comprensión auditiva.

Abstract: Although the Spanish manuals focus on multiple-choice or cloze listening exercises, the benefit of working with different types of dictation in the classroom is undeniable, as it facilitates the acquisition of semantic structures of the language in the learner while the learner identifies the words for subsequent transcription by checking the spelling. This work takes as a reference the premise that dictations can be a great ally for the acquisition of orthography and focuses mainly on a didactic proposal based on a cohort of dictations for a student body of Italian origin of level C1-C2 which encompasses the most important orthographic conventions contained in the orthography of the Spanish language 
of the RAE and in the Curricular Plan of the Instituto Cervantes. The later work of the error and of the compared spelling of the Spanish and the Italian will constitute the second objective.

Keywords: Orthography. Dictation. Interlanguage. Listening comprehension.

\section{El dictado como método de evaluación}

Muchos han sido los argumentos a favor y en contra del dictado (y en especial contra el tradicional), si bien ha sido y continúa siendo el método para evaluar la ortografía por excelencia ${ }^{1}$. En opinión de los estudiosos, esta actividad refleja poco contacto con la realidad; tanto es así, que algunos autores desaconsejan su práctica porque "no representa una habilidad que el estudiante deba mostrar en su vida diaria" (Benítez 1988: 30), "pues se trata de un ejercicio que no encuentra paragón en la práctica habitual de los hablantes de una comunidad" (Moya y García 1988: 204).

El ejercicio del dictado posee una gran rentabilidad ${ }^{2}$ para la psicolingüística cognitiva, ya que "el dictado resulta ser un proceso intelectual mediante el cual la lengua oral que se recibe como entrada lingüística, se transforma en salida escrita. Es decir, constituye una transformación psicolingüística de lengua oral a lengua escrita" (Fraca 2007: 96). En esta transformación, el alumno debe convertir "la huella acústica" en representación gráfica, para luego localizar en la "huella visual" la palabra que corresponda (ibidem: 98). Para muchos autores, la falta de dicha huella implicaría una escasa práctica de la lectura en el alumnado, y algunos, como Sánchez (citado en Fernández-Rufete 2015: 10), consideran que "la lectura es un óptimo auxiliar de la ortografía porque contribuye a reforzar la imagen léxica que tiene el alumno de las palabras, afianzando el léxico que ya conoce". Dicha aseveración encontraría una estrecha relación con la disminución del

\footnotetext{
${ }^{1}$ Fraca asegura que "la práctica del dictado es uno de los ejercicios escolares más utilizados para enseñar, evaluar y aprender el adecuado uso de los grafemas, la tildación, el empleo de mayúsculas y minúsculas, entre otros aspectos formales de la lengua escrita" (2007: 96). De igual manera, estamos de acuerdo con Cassany (2004: 231) en la productividad del dictado, al afirmar que "al margen del tipo de alumnado [...], de la metodología seguida [...] e incluso del contexto de aprendizaje $[. .$.$] , la tarea de comprender un texto oral y codificarlo al canal escrito ofrece un interés$ intrínseco indiscutible y evidentes posibilidades didácticas".

${ }^{2}$ La rentabilidad a la que nos referimos puede ser descrita eficazmente a través del círculo de interrelación entre destrezas de Moya y García, por el cual a la comprensión auditiva le corresponde la producción oral, mientras que a la producción escrita le corresponde la comprensión lectora (1988: 207).
} 
Ortografía a través de los dictados: propuesta didáctica para italófonos

hábito de la lectura en los jóvenes ${ }^{3}$, lo cual cristaliza en errores ortográficos en la propia lengua a lo largo de la etapa educativa, llegando a la educación universitaria. Esto representaría, a nuestro modo de ver, la dificultad de aprender con una cierta rigurosidad la ortografía en otro idioma. En el caso de la lengua española, los instrumentos de evaluación internacionales oficiales que certifican el nivel de idioma a extranjeros, a través de las cuatro destrezas, son el SIELE, el DELE, el CELU y el DIE. Sin embargo, ninguno de ellos tiene en cuenta la prueba del dictado, esencial, en nuestra opinión, para verificar la adquisición de los esquemas fonéticos y la ortografía de la lengua. Además, la transcripción nos proporcionaría más datos sobre el nivel de nuestros alumnos, ya que, además de lo anterior, mediría "también su comprensión oral, por lo que resultaría un buen instrumento para medir el conocimiento global que se tiene de una lengua" (Benítez 1988: 33). Dicho ejercicio, para que no careciera de contexto, podría englobar los temas de la comprensión lectora y auditiva del resto de las pruebas del examen, puesto que, siendo los temas de los DELE concretos, presumiblemente no resultarían nuevos al candidato. A continuación, se muestran los temas que comprenden los libros de Edelsa de preparación al DELE C1 y C2 y que los dictados podrían abarcar.

\begin{tabular}{|l|l|}
\hline Libro C1 Edelsa & Libro C2 Edelsa \\
\hline Educación y formación (examen 1) & Medios de comunicación (examen 1) \\
Bienestar y salud (examen 2) & Historia y artes (examen 2) \\
Mundo laboral (examen 3) & Sentimientos, creencias y valores \\
$\begin{array}{l}\text { Ciencia, tecnología y transportes } \\
\text { (examen 4) }\end{array}$ & (examen 3) \\
$\begin{array}{l}\text { Manifestaciones artísticas (examen 5) } \\
\text { Medios de comunicación y deportes } \\
\text { (examen 6) }\end{array}$ & Economía y desarrollo (examen 5) \\
\hline
\end{tabular}

Tabla 1. Contenidos de los libros C1-C2

\section{Tipos de dictados y sus ventajas}

Entre las ventajas del dictado podemos encontrar principalmente la duración de la tarea, que podría ocupar varios minutos de explotación didáctica; la práctica de la expresión escrita; el descubrimiento y ejercitación de sonidos a los que el

${ }^{3}$ El Barómetro de los Hábitos de Lectura y Compra de Libros en España del año 2017 de la Federación de Gremios de Editores de España (FGEE) concluye que a partir de la edad de 10 años se verifica un deterioro de la práctica de la lectura (entre los 10 y 14 años los sujetos que leen representan un $80 \%$, mientras que entre los 15 y los 18 años descienden al $55 \%$ ), además del hábito de estudiar en las bibliotecas. 


\section{RubÉN GONZÁLEZ VALLEJO}

alumno no está acostumbrado; y la corrección y aprendizaje de sus propios errores (Benítez 1988: 25). Asimismo, (ibidem: 35) otras razones que pueden justificar su uso son su propuesta como actividad de calentamiento, su flexibilidad de inserción entre dos tareas, la introducción de elementos culturales en el aula de español y de aspectos gramaticales objeto de nuestra unidad (por ejemplo, un dictado basado en los problemáticos verbos ser y estar). En esta óptica, es deber del profesor acercarse, en la medida de lo posible, a la interlengua ${ }^{4}$ creada para abordar los problemas del alumnado con mayor determinación. Algunos de los problemas para los italófonos son el binomio ser y estar, y por y para; mientras que, por ejemplo, para los anglófonos uno de los escollos principales es la pronunciación e identificación de "las dentales" (Benítez 1988: 36). Por lo tanto, la selección de los textos debe ser atentamente sometida a nuestra criba didáctica.

Una de las críticas argüidas en contra del dictado ha sido su fragmentación ${ }^{5}$ en unidades carentes de entonación y con presencia de anacolutos, en relación con una pronunciación no equilibrada. Esta debe ser el punto neurálgico de la presentación del dictado, pues de la misma depende en gran medida el éxito de los estudiantes.

A continuación, y a modo de ejemplo, en las tablas 2 y 3 se presentan frases idénticas con acotaciones diferentes ${ }^{6}$, las cuales representan un cambio en el esquema tonal. Esto pone en evidencia que los signos ortográficos están estrechamente ligados a la pronunciación; de ahí que la buena realización de esta sea esencial para el éxito de la actividad.

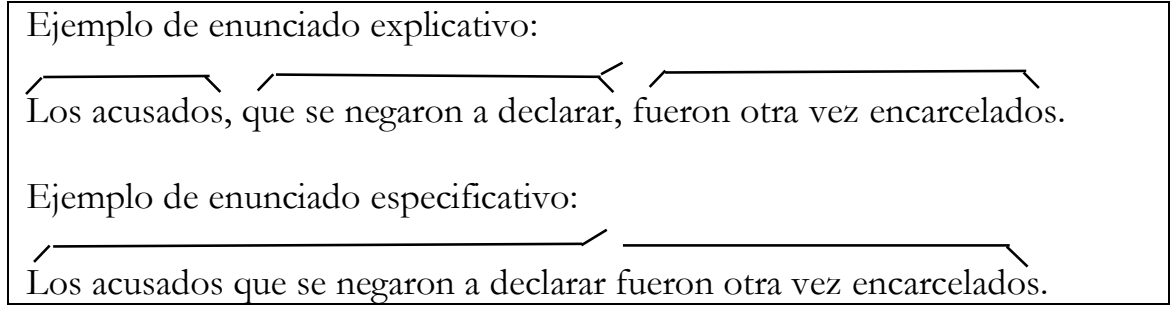

Tabla 2. Ejemplo con esquema tonal de enunciado explicativo y especificativo

\footnotetext{
${ }^{4}$ Entendemos el concepto de interlengua como "lengua híbrida [del estudiante] que contiene elementos lingüísticos de su lengua materna y de su lengua que se encuentra aprendiendo" (Roldán 1989: 11).

${ }^{5}$ Con el término fragmentación nos referimos a la división de la unidad textual en otras más pequeñas dotadas de coherencia y significado.

${ }^{6}$ Las frases expuestas han sido extraídas del libro Sueña 4 (nivel C1) de Anaya (AAVV 2008: 101).
} 


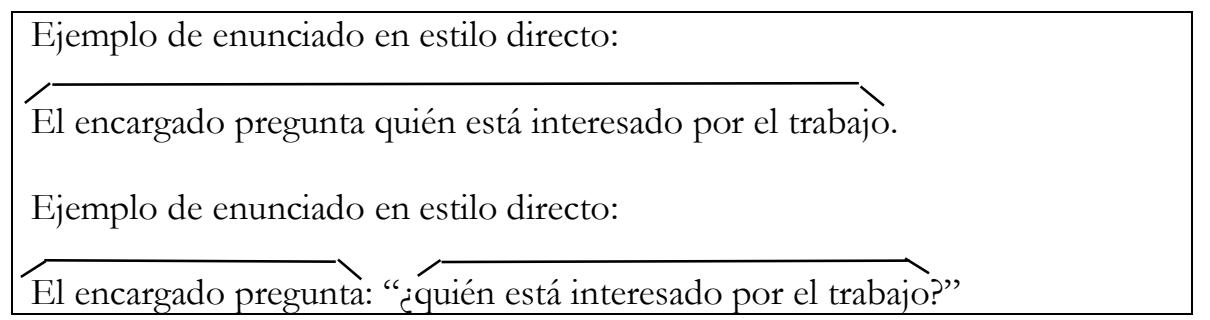

Tabla 3. Ejemplo con esquema tonal de enunciado de estilo directo e indirecto

La falta de una entonación eficaz de dichas frases representaría una imprecisión en la huella acústica del alumno, y a su vez se traduciría en una estructura incomprensible (uno de los cometidos del profesor para el éxito del dictado es que sus alumnos comprendan íntegramente el dictado). Por otra parte, tenemos otro tipo de unidades fragmentadas carentes de entonación, que serían, en palabras de Moya y García, "extrañas frases creadas exprofeso para estos ejercicios del tipo 'Ahí hay un hombre que dice ¡Ay!' o textos literarios, con frecuencia extraídos del Quijote" (1988: 204). Por lo tanto, podemos subrayar que el pilar fundamental del dictado son los silencios y los enunciados dotados de significado y coherencia, ya que como bien afirman estos autores, "si en una frase se inserta una palabra desconocida por el receptor, lo más probable es que dicha palabra no sea percibida con claridad" (ibidem: 207). Sin embargo, si dicho vocablo encuentra su sentido sintáctico dentro de una frase, el contexto puede reducir la imprecisión de la huella acústica mediante un "profundo conocimiento de las unidades y funcionamiento de la lengua" (ibidem: 209).

Por otra parte, "la puntuación puede cambiar el significado de las palabras escritas" (Cassany 2004: 236). A este respecto, las llamadas palabras tritónicas, que pueden llevar acento en cada una de sus sílabas, representan el ejemplo estrella. Por ejemplo, desplazando el golpe de voz, la palabra esdrújula género (sustantivo), se convierte en la palabra llana genero (primera persona singular del indicativo presente del verbo 'generar') o en generó (tercera persona singular del pretérito indefinido del mismo verbo). Otros casos serían ánimo, animo y animó; práctico, practico y práctico; o específico, especifico, especificó, entre una larga lista de elementos tritónicos.

En cuanto a la clasificación que Cassany (2004: 234-247) realiza de los diferentes dictados que se pueden llevar a cabo, encontramos:

1. Dictado tradicional. Consiste en la transcripción escrita del texto dictado por el profesor, cuyo objetivo principal es evidenciar la ortografía y los principales errores. 


\section{RubÉN GONZÁLEZ VALLEJO}

2. Dictado por parejas. Consiste en dividir el trabajo entre dos alumnos: uno dicta y el otro transcribe. La ventaja principal es la implicación en la actividad por parte de los estudiantes.

3. Dictado de secretaria. Consiste en la producción oral de un texto a velocidad normal a un grupo de estudiantes, los cuales, ejercitándose con la memoria y la toma de apuntes, deberán anotar lo que puedan para luego reconstruir el mensaje entre todos.

4. Dictado colectivo. Consiste en la realización de un dictado por parte de todos los alumnos a través de un esquema facilitado por el docente, como, por ejemplo, la introducción de un personaje para el que posteriormente hay que inventar una historia y desarrollarla.

5. Dictado en grupo. En esta ocasión, los estudiantes crean frases a través de un tema propuesto por el profesor. Posteriormente crean grupos y se dictan las frases recíprocamente. Por último, para su corrección, dispondrán de libros de consulta y de la ayuda del profesor.

6. Medio dictado. Consiste en la introducción de frases libres por parte del estudiante al texto del dictado, por ejemplo, para añadir algún detalle o aspecto a la historia que se le presenta.

7. Dictado gramatical. Consiste en la práctica de algún aspecto gramatical, que el estudiante trabajará variando las frases dictadas (por ejemplo, realizando la transformación de las frases del singular al plural o del presente al pasado).

8. Dictado telegráfico. Consiste en la producción de frases compuestas por palabras semánticamente con significado y sin presencia de elementos gramaticales, como artículos o preposiciones, que más tarde deberá completar el estudiante.

9. Dictado trampolin. Consiste en la producción oral no de un verdadero dictado, sino más bien del texto que normalmente se escribiría en la pizarra para que los estudiantes copiaran en el contexto de la explicación de un concepto. Esta metodología provoca una mayor atención del estudiante y sirve de palanca al profesor para introducir la siguiente actividad.

10. Dictado de pared. Consiste en un juego de rol entre un estudiante que desempeña la función de escriba y otro la de mensajero (este dicta al primero un mensaje que ha leído en la pared para su transcripción). Es un dictado útil para el desarrollo de la memoria y fomenta el protagonismo entre los estudiantes.

11. Dictado de dibujos. Consiste, en la clase de Plástica, en el dictado de figuras que deben ser representadas gráficamente por los estudiantes.

Además de los trabajos de Cassany, como el que acabamos de exponer, otros, como el de Tena de 1999 o el blog de De la Torre García y García Torralbo 
Ortografía a través de los dictados: propuesta didáctica para italófonos

(citados en Hernández 2011: 69), representan una fuente variada de la visión dinámica de los dictados.

En cuanto a las ventajas que ofrece el método del dictado, que ya en las primeras líneas de este epígrafe adelantábamos, enunciamos a continuación una síntesis de las mejores de entre las propuestas por García y Moya (1988: 210), y Hernández (2011: 69-71):

En cuanto al profesor, podemos alistar:

a) Sirve como ejercicio de calentamiento que permite implicar a toda la clase;

b) Puede identificar diversas dificultades procedentes de la interlengua de los estudiantes sobre las que trabajar en un plazo de tiempo reducido;

c) Sirve para introducir o consolidar contenidos gramaticales o culturales, entre otros;

d) Ofrece una amplia gama de posibilidades de realización (supra).

En cuanto al estudiante, en cambio:

a) Es un método directo de adquisición de la ortografía;

b) Permite la autocorrección;

c) Agiliza la práctica de la escritura según los ritmos del dictado;

d) El estudiante toma conciencia de sus inseguridades ortográficas y en la lengua;

e) Mejora la comprensión auditiva y la comprensión lectora directamente, y el bagaje lingüístico indirectamente;

f) Se adapta a las necesidades o límites del alumnado;

g) Le ayuda a tomar conciencia de su interlengua y a evolucionar en la misma.

En cuanto a las desventajas, concluimos con el pensamiento de Hernández, quien piensa que las desventajas pueden ser igualmente numerosas como las ventajas, si se tiene en consideración "todos los usos inadecuados o poco pertinentes que se puedan hacer de ella [práctica del dictado]" (2011: 71).

\section{Propuesta didáctica a italófonos. Muestra de modelos reales}

De acuerdo con muchos autores ${ }^{7}$, el presente trabajo toma como referencia la premisa de que los dictados pueden ser un gran aliado para la adquisición de la ortografía, ya que es innegable la vasta gama de explotaciones didácticas que podemos llevar a cabo a través de las diversas variantes que hemos reflejado en

\footnotetext{
7 "La mayoría de autores y manuales (Gómez 2007; Bustos 1995; Palacios 2010 y Martínez 2004) coinciden en un enfoque tradicional para enseñar ortografía y otros consideran que es el más empleado por el profesorado (Mesanza 1991; Díaz 2008 y Barberá et al. 2001)”. (Fernández-Rufete 2015: 9).
} 


\section{RuBÉN GONZÁLEZ VALLEJO}

el apartado anterior. De todas ellas, nos hemos centrado en el dictado tradicional ${ }^{8}$ a través de textos creados exprofeso en función de las convenciones ortográficas más importantes recogidas en la Ortografía de la lengua española de la RAE y en el Plan Curricular del Instituto Cervantes. Esto se debe a que la lengua española, como lengua afín, permite un alto nivel de comprensión para los italófonos, y situándonos en un contexto universitario, en el último año de la carrera de Mediación Lingüística, exige una interiorización mayor de los contenidos ortotipográficos que van más allá de la simple línea teórica.

En cuanto a los contenidos ortográficos, en un nivel de salida B la ortografía ya ha abarcado el principal uso de las mayúsculas, los diversos sonidos consonánticos, el tratamiento de las voces provenientes de otros idiomas y los usos principales de los signos ortográficos ${ }^{9}$. Por ello, nuestros dictados se han perfilado en busca de un contexto para trabajar detalladamente los contenidos ortográficos que mostramos en la Tabla 4 relativos al nivel C y adaptados del Plan Curricular del Instituto Cervantes.

\begin{tabular}{|l|l|l|l|}
\hline Homófonos & Dígrafos (ll y rr) & $\begin{array}{l}\text { Tratamiento de } \\
\text { los prefijos }\end{array}$ & $\begin{array}{l}\text { Tratamiento de } \\
\text { las palabras } \\
\text { compuestas }\end{array}$ \\
\hline $\begin{array}{l}\text { Expresión de } \\
\text { las cifras y los } \\
\text { números } \\
\text { (incluyendo los } \\
\text { romanos) }\end{array}$ & $\begin{array}{l}\text { Tipo de letra } \\
\text { (cursiva, } \\
\text { subrayado, } \\
\text { negrita) }\end{array}$ & $\begin{array}{l}\text { Tratamiento de } \\
\text { los extranjerismos }\end{array}$ & $\begin{array}{l}\text { Voces } \\
\text { provenientes de } \\
\text { otras lenguas } \\
\text { (adaptación) }\end{array}$ \\
\hline $\begin{array}{l}\text { Doble acentuación } \\
\text { (diferencia } \\
\text { fónica entre } \\
\begin{array}{l}\text { España y } \\
\text { Latinoamérica) }\end{array}\end{array}$ & $\begin{array}{l}\text { Usos más } \\
\text { avanzados de los } \\
\text { signos } \\
\text { ortográficos }\end{array}$ & $\begin{array}{l}\text { Tratamiento de } \\
\text { las siglas y las } \\
\text { abreviaturas }\end{array}$ & $\begin{array}{l}\text { Contracción de } \\
\text { dos vocales } \\
\text { iguales }\end{array}$ \\
\hline
\end{tabular}

\footnotetext{
8 Si bien hay quien, como Cassany, considera que el dictado tradicional se asocia a un concepto conservador y restrictivo de la gramática que aborda la memorización de reglas de ortografía y que concibe el error como un elemento penalizador (Cassany 2004: 231).

9 Para obtener más información en cuanto a la ortografía dedicada a cada nivel de la lengua española, El Plan Curricular del Instituto Cervantes representa un óptimo recurso de comparación entre pares de niveles próximos A1-A2, B1-B2, C1-C2:

[https://cvc.cervantes.es/ensenanza/biblioteca_ele/plan_curricular/niveles/04_ortografia_inven tario_b1-b2.htm].
} 
Ortografía a través de los dictados: propuesta didáctica para italófonos

\begin{tabular}{|l|l|l|l|}
\hline $\begin{array}{l}\text { Diferencia b/v, } \\
\mathrm{ll} / \mathrm{y}\end{array}$ & $\begin{array}{l}\text { Diptongos } \\
\text { triptongos }\end{array}$ & Onomatopeyas & $\begin{array}{l}\text { Tratamiento de } \\
\text { los títulos }\end{array}$ \\
\hline La $b$ intercalada & La $x$ & $\begin{array}{l}\text { Palabras de doble } \\
\text { escritura }\end{array}$ & $\begin{array}{l}\text { Palabras } \\
\text { tritónicas }\end{array}$ \\
\hline Diéresis & Interjección & $\begin{array}{l}\text { Los diálogos y los incisos con la barra, } \\
\text { mayúsculas y minúsculas (cargos, } \\
\text { incisos entre comillas, etc.). }\end{array}$ \\
\hline
\end{tabular}

Tabla 4. Contenido ortográfico de los dictados

Las secuencias didácticas, compuestas por el contenido previamente presentado y posteriormente revisado en el dictado y reforzado en la producción escrita, han permitido que los estudiantes tomen conciencia del error $\mathrm{y}$, por consecuencia, han facilitado el posterior trabajo contrastivo de la ortografía en español y en italiano ${ }^{10}$. Este último punto lo hemos considerado de gran importancia en el proceso de aprendizaje. Si bien el mero ejercicio del dictado promueve la adquisición de estructuras semánticas y gramaticales de la lengua en el discente (a la vez que este identifica las palabras para su posterior transcripción revisando la ortografía), si no se alcanza una fuerte adquisición de la ortografía de nuestra lengua, difícilmente se consolidará la de la lengua estudiada al carecer de una "huella visual" que permita la comparación y la adquisición. Por ello, después de observar los contenidos ortográficos presentes en el dictado en español, hemos comparado su uso en la lengua italiana, pues se ha constatado, fruto de otras experiencias, que el estudio de la ortografía flaquea tanto en el sistema educativo español como en el italiano. A este respecto, Medina constata que, si bien se haya dedicado mucho esfuerzo en la escuela a la adquisición de la ortografía, los resultados de esta en los estudiantes nunca han sido proporcionales (1994: 74).

En cuanto a aspectos como el de las homofonías, que producen un despiste en la huella visual del estudiante, Cassany opina que "se tienen que controlar [...], con el fin de evitar que los alumnos se confundan y que aprendan a distinguirlas"

${ }^{10} \mathrm{~A}$ modo de ejemplo, en el caso del dictado n. ${ }^{\circ} 1$ que a continuación se presentará, el contenido se presentó a través de la lectura y de un análisis inductivo de las reglas de ortografía presentes en el artículo "Colau: 'Después de mis hijos, la PAH es lo mejor que me ha pasado"' 25 de febrero de 2019) de El País, pues los elementos tratados, como el diferente uso de las mayúsculas, las siglas, los prefijos y los préstamos abundan en el lenguaje periodístico. Posteriormente, y a modo de comparación, se llevó a cabo el estudio y análisis de la noticia "Norvegia, il super fondo diventa più 'green': inizia il taglio agli investimenti in petrolio e gas" (8 de marzo de 2019), extraída del periódico Il Corriere della Sera. Por último, y a fin de evitar las posibles licencias deliberadas, se cotejó la respectiva teoría de dichos contenidos extraída de la Ortografía de la Lengua Española y de la Accademia della Crusca. 
(2004: 236). En nuestros dictados, las homofonías se han introducido gradualmente en los dictados de manera que el estudiante pudiera reconocer su grafía analizando los campos semánticos. Por ejemplo: en la frase "iba por las mañanas con la vacada al monte", se espera que el discente de nivel C1-C2 asocie la palabra vacada a vaca, pues en verano estos animales suelen pastar en dicha zona.

A continuación, se muestra nuestra propuesta didáctica compuesta por una cohorte de dictados (once), fruto de nuestra imaginación. Como hemos mencionado anteriormente, los textos se han realizado con base en las normas ortográficas del Plan Curricular del Cervantes y de la Ortografía de la lengua española. Junto a ellos, se muestran los contenidos presentes en cada uno de los textos, con vistas a consolidarlos posteriormente o presentarlos previamente mediante otras actividades adicionales.

\begin{tabular}{|c|c|}
\hline Dictado n. $^{\circ} 1$ & \\
\hline Contenidos & \\
\hline $\begin{array}{l}\text { - La } b \text { intercalada } \\
\text { - Préstamos adaptados } \\
\text { - Prefijos } \\
\text { - Tratamiento de los títulos }\end{array}$ & $\begin{array}{l}\text { - Tratamiento de las siglas } \\
\text { - Palabras de doble escritura } \\
\text { - Uso de las comillas y } \\
\text { mayúsculas }\end{array}$ \\
\hline Texto & \\
\hline $\begin{array}{l}\text { Se sentó en aquella oscura buhardil } \\
\text { leía su currículum vítae y sostenía } \\
\text { caído enferma y el pensamiento de } \\
\text { de tu casa. Como el soldado de la ex } \\
\text { en encarar el rifle que había per } \\
\text { Descolgó el teléfono, llamó a la } \\
\text { Hipoteca) y gritó con vehemencia: } \\
\text { conque después os sentiréis mal po }\end{array}$ & $\begin{array}{l}\text { la luz tenue de una vela, mientras } \\
\text { tano un cruasán. Su exmujer había } \\
\text { sahuciado le recordó el libro Cerca } \\
\text { slavia que era, no dudó un instante } \\
\text { do a los Hernández años atrás. } \\
\text { (Plataforma de Afectados por la } \\
\text { es el arma con que me dispararé, } \\
\text { aberme ayudado". }\end{array}$ \\
\hline
\end{tabular}

\begin{tabular}{|l|l|}
\hline \multicolumn{2}{|l|}{ Dictado n. $^{\circ} 2$} \\
\hline Contenidos \\
\hline • Interjecciones & $\bullet \quad$ Palabras de doble escritura \\
- Préstamos adaptados & $\bullet \quad$ Uso de las comillas y \\
- Homofonías & mayúsculas \\
- Palabras con dobles vocales & - Palabras tritónicas \\
\hline Texto \\
\hline "Los ultimátums son palabras prósperas de un atisbo de esperanza". Cerré la \\
puerta en cuanto lo escuché. Acababa de regresar de El Cairo, y harto de los \\
\hline
\end{tabular}


Ortografía a través de los dictados: propuesta didáctica para italófonos

insulsos versos de los que abusaba aquella aya, me encerré en la alacena. Nunca fui un creedor de tales artimañas. El júbilo de los días anteriores desapareció en un suspiro. Pateé el sillón y me senté en él mirando hacia la ventana. De repente, vi al proveedor neerlandés, con el que me peleé un hermoso día de primavera, saltar la valla que estaba cerca del haya. En ese momento sentí curiosidad por que se cayera y, efectivamente, al mirarme, no advirtió la piedra y gritó: ¡Ay!

\begin{tabular}{|c|c|}
\hline Dictado n. 3 & \\
\hline Contenidos & \\
\hline $\begin{array}{l}\text { - La } b \text { intercalada } \\
\text { - Homofonías }\end{array}$ & $\begin{array}{l}\text { - Uso de las mayúsculas } \\
\text { (apodos, antonomasias, } \\
\text { ideas figuradas, eventos) }\end{array}$ \\
\hline Texto & \\
\hline $\begin{array}{l}\text { Corría el año } 1530 \text {. Pedrc } \\
\text { por el viaje, durmió en un } \\
\text { Las paredes enmohecida } \\
\text { salió al balcón para respir } \\
\text { Desde allí, pudo observar } \\
\text { invierno. Al día siguient } \\
\text { Española de Lingüística e } \\
\text { con Jimena, la alcahueta }\end{array}$ & $\begin{array}{l}\text { ó a la Ciudad Eterna, y exhausto } \\
\text { donde pudo conocer a la Muerte. } \\
\text { a inhalar correctamente, así que } \\
\text { erza el aire de aquel frío infernal. } \\
\text { nante dirigiéndose a la dehesa de } \\
\text { rimer Simposio de la Sociedad } \\
\text { lología y sabía que se encontraría } \\
\text { sentaría un día a su futura mujer. }\end{array}$ \\
\hline
\end{tabular}

\begin{tabular}{|c|c|}
\hline Dictado n. ${ }^{\circ} 4$ & \\
\hline Contenidos & \\
\hline $\begin{array}{ll}\text { - } & \text { Prefijo -pos }(t) \\
\text { - } & \text { Diferencia } y / l l \\
\text { - } & \text { Pronunciación } z \text { final } \\
\text { - } & \text { Palabras con doble escritura }\end{array}$ & $\begin{array}{l}\text { - Palabras de doble escritura } \\
\text { - Uso de las mayúsculas } \\
\text { - Upellidos, topónimos) } \\
\text { Uso de las mayúsculas y } \\
\text { minúsculas después de } \\
\text { puntos suspensivos en } \\
\text { función de la conexión con } \\
\text { la anterior frase }\end{array}$ \\
\hline Texto & \\
\hline $\begin{array}{l}\text { La señora Del Arco trabaja de más, } \\
\text { puso el sobretodo y se marchó... per } \\
\text { Necesitaba decorar su casa y record }\end{array}$ & $\begin{array}{l}\text { siempre lo decía. Aquel día se } \\
\text { se lamentó, aparte la secretaria. } \\
\text { abras del basto de su padre, el } \\
\text { degó a la montaña. El callo le }\end{array}$ \\
\hline
\end{tabular}


dolía desde que se cayó, y el hecho de que no hallaba una solución al problema le hizo sentarse en el poyo a pensar. Aprehendió un libro de medicina de la pos(t)guerra para hojearlo y leyó el pseudónimo del autor... Vivía en las islas Canarias y conocía a parte de los habitantes por lo que, de un momento a otro, alguien la llevaría a casa en coche.

\begin{tabular}{|l|l|}
\hline \multicolumn{2}{|l|}{ Dictado n. $^{\circ} 5$} \\
\hline Contenidos \\
\hline \multicolumn{1}{|c|}{ Diéresis } & $\begin{array}{l}\text { Futuro de subjuntivo } \\
\text { (contenido gramatical) }\end{array}$ \\
\hline Texto \\
\hline $\begin{array}{l}\text { Quien violare la siguiente premisa, de muchos conocimientos carece. Todos } \\
\text { los que vieren y entendieren el bilingüismo, y apacigüen la encrucijada } \\
\text { lingǘstica entre dos personas, será un salvador. Cuando una persona pidiere } \\
\text { o hubiere pedido información sin éxito, quienes tuvieren modo de responder, } \\
\text { lo hagan, pues no es pedigüeña una persona que pide sin temor lo que no } \\
\text { entiende. Argüir a una persona que no conoce un idioma su falta de } \\
\text { conocimiento, es reconocer untarse el ungüento de la ignorancia por doquier. } \\
\text { Aprender de otras culturas es importante, por lo que, a donde fueres, haz lo } \\
\text { que vieres. }\end{array}$ \\
\hline
\end{tabular}

\begin{tabular}{|c|c|}
\hline \multicolumn{2}{|l|}{ Dictado n. ${ }^{\circ} 6$} \\
\hline \multicolumn{2}{|l|}{ Contenidos } \\
\hline $\begin{array}{l}\text { - Tratamiento de los prefijos } \\
\text { y los fonemas con las barras } \\
\text { - Uso del guion } \\
\text { - Voces provenientes de otras } \\
\text { lenguas }\end{array}$ & $\begin{array}{l}\text { - Interjección } \\
\text { - Jerarquía de las comillas } \\
\text { (comillas angulares, latinas y } \\
\text { simples) }\end{array}$ \\
\hline \multicolumn{2}{|l|}{ Texto } \\
\hline \multicolumn{2}{|c|}{$\begin{array}{l}\text { Estaba cansado de escribir palabras que contuvieran el prefijo neo- y el } \\
\text { fonema / } \mathrm{t} / \text {, así que bajé a la biblioteca donde aquel día recitaban libros. Se } \\
\text { trataba de la lectura de una novela post mortem y aquel fragmento en sí no tenía } \\
\text { sentido. ¿Qué era eso de que el granjero novel que comía bayas llevaba a una } \\
\text { vaca en la baca del coche? Tenía menos sentido que cuando encontró a la } \\
\text { bacante que acusaba un dolor alvino junto a un hombre alado. En ese }\end{array}$} \\
\hline
\end{tabular}

${ }^{11}$ En este caso, el dictado sirvió para presentar el futuro de subjuntivo en el nivel C2, recurrente en los textos jurídicos que los estudiantes manejaban en la asignatura de Traducción. 
Ortografía a través de los dictados: propuesta didáctica para italófonos

momento le arrebaté el libro de las manos al tipo y leí el siguiente fragmento: "Los días soleados como este — comentó Silvia- me encantan, ja, ja, ja". Me quedé sin palabras de lo tonto que era aquel libro, sin embargo, años después, me seguí acordando de una frase que aparecía al final del capítulo: "Cuando mi padre llegó a casa, me dijo: "Mañana nos mudamos de esta 'casa' para vivir realmente en un nuevo hogar".

\begin{tabular}{|c|c|}
\hline Dictado n. ${ }^{\circ} 7$ & \\
\hline Contenidos & \\
\hline $\begin{array}{l}\text { - Tratamiento de las palabras } \\
\text { compuestas } \\
\text { - } \text { Homofonías } \\
\text { - Tratamiento de los prefijos }\end{array}$ & $\begin{array}{l}\text { - Tratamiento de las siglas } \\
\text { - } \quad \text { Contracción de dos vocales } \\
\text { iguales } \\
\text { - } \quad \text { Palabras con doble escritura }\end{array}$ \\
\hline Texto & \\
\hline $\begin{array}{l}\text { A media noche decidí coger el trat } \\
\text { cansada del coche-cama en el que } \\
\text { conocimientos lingüístico-literarios } \\
\text { fondo en el habar de su padre, despu } \\
\text { hizo una billa fantástica junto a aque } \\
\text { subvenía cada vez que lo llamaba, si l } \\
\text { cubrían con un tejido de algodón } \\
\text { altorrelieve que presentó en la mi }\end{array}$ & $\begin{array}{l}\text { tico para ver a Marcos, estaba } \\
\text { a. Él era catalanoparlante y sus } \\
\text { pasionaban. Nos conocimos a } \\
\text { aquellas partidas en el bar donde } \\
\text { bocal. No era un inepto porque } \\
\text { parecía vendiendo polainas que } \\
\text { reempeine. El día que vi aquel } \\
\text { me quedé horrorizada. Había } \\
\text { veía porque era un boto. }\end{array}$ \\
\hline
\end{tabular}

\begin{tabular}{|c|c|}
\hline Dictado n. ${ }^{\circ} 8$ & \\
\hline Contenidos & \\
\hline $\begin{array}{l}\text { - Diptongos e hiatos } \\
\text { - Voces provenientes de } \\
\text { otras lenguas } \\
\end{array}$ & $\begin{array}{l}\text { - Diferencia } y / l l \\
\text { - Contracción de dos vocales } \\
\text { iguales }\end{array}$ \\
\hline Texto & \\
\hline $\begin{array}{l}\text { Mis hijos nunca compartieron gusto } \\
\text { Ándalus y deseaba convertirse en } \\
\text { fascinaban los saharauis. El primero } \\
\text { mientras que el segundo era un dejad } \\
\text { tenía el brazo enyesado por ser un } \\
\text { embarcaciones, mientras que el otrc }\end{array}$ & $\begin{array}{l}\text { Larón le gustaba la historia de al- } \\
\text { uunvir, mientras que a Isaac le } \\
\text { yunque y mordía como un yacaré, } \\
\text { osso modo, un truhan. Uno siempre } \\
\text { añado y se dedicaba a boyar las } \\
\text { gía yucas y yuyos durante millas }\end{array}$ \\
\hline
\end{tabular}


que no píen dinero como siempre hacen y ellos mismos saben que cuando uno falte, como siempre se dice, "el muerto al hoyo y el vivo al bollo".

\begin{tabular}{|c|c|}
\hline Dictado n. ${ }^{\circ} 9$ & \\
\hline Contenidos & \\
\hline $\begin{array}{l}\text { - Diptongos e hiatos } \\
\text { - Palabras compuestas con el } \\
\text { dígrafo rr } \\
\text { - Uso de las mayúsculas } \\
\text { (eventos) }\end{array}$ & 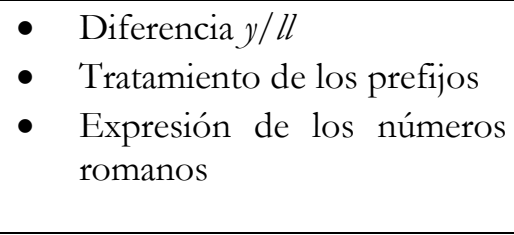 \\
\hline Texto & \\
\hline $\begin{array}{l}\text { Fue al VI Congreso Internacional de } \\
\text { más interesante ver cómo crecía una } \\
\text { doscientas personas. Acabaron debati } \\
\text { quien decidía todo. Él siempre habí } \\
\text { Cervantes en el tomo III, página XVI } \\
\text { Perogrullo. Zaherido, salió a mita } \\
\text { hiperresponsable puertorriqueño que } \\
\text { del tiempo escuchando en la autorra } \\
\text { creación del primer nanorrobot. Aqu } \\
\text { un recóndito restaurante y pensó } \\
\text { camareras que no paraban de reírse e }\end{array}$ & $\begin{array}{l}\text { ngua Española y le pareció que era } \\
\text { aba en un azufaifo. Acudieron mil } \\
\text { osobre si era la casualidad o el sino } \\
\text { ído en el hado y en lo que decía } \\
\text { prólogo. Para él era una verdad de } \\
\text { nfadado con aquel superrico e } \\
\text { santaba el congreso y pasó el resto } \\
\text { os nuevos farmacorresistentes y la } \\
\text { noche cenó una pizza deletérea en } \\
\text { la sororidad entre aquellas dos } \\
\text { temporánea. }\end{array}$ \\
\hline
\end{tabular}

\begin{tabular}{|c|c|}
\hline \multirow{2}{*}{\multicolumn{2}{|c|}{$\begin{array}{l}\text { Dictado n. }{ }^{\circ} 10 \\
\text { Contenidos }\end{array}$}} \\
\hline & \\
\hline $\begin{array}{ll}\text { - } & \text { Hiatos } \\
\text { - } & \text { Trabalenguas } \\
\end{array}$ & $\begin{array}{l}\text { - Tratamiento de las palabras } \\
\text { compuestas } \\
\text { - Usos metalingüísticos de las } \\
\text { comillas }\end{array}$ \\
\hline \multicolumn{2}{|r|}{ - } \\
\hline \multicolumn{2}{|c|}{$\begin{array}{l}\text { Érase un padre y sus dos hijos. El pequeño, habiendo aprendido aquella } \\
\text { mañana varios trabalenguas, dio muestra de su inteligencia y pronunció: "En } \\
\text { una zarzamorera estaba una mariposa zarzarrosa y cuando la mariposa } \\
\text { zarzarrosaba, las zarzamoras mariposeaban". Al escucharlo, su hermano } \\
\text { mayor, que siempre intentaba ser el mejor, respondió con otro trabalenguas, }\end{array}$} \\
\hline
\end{tabular}

12 Consideramos que los trabalenguas son una forma lúdica de enseñar, pues su ingenio siempre provoca una sonrisa en el lector, y exigen aguzar el oído para discernir los sonidos semejantes. 
Ortografía a través de los dictados: propuesta didáctica para italófonos

y dijo: "Para la Lola una lila le di a la Adela, mas la tomó la Dalila y yo le dije a Adela que dijera a Dalila que le diera la lila a la Lola". Ante este sinsentido, el padre decidió derrotar a los hijos y les propuso: "Ganará quien sepa pronunciar de carrerilla sin equivocarse las palabras 'electroencefalografista', 'esternocleidomastoideo', 'electroencefalografía', 'electroencefalograma', 'paralelepípedo’ y 'otorrinolaringólogo"'.

\begin{tabular}{|l|l|}
\hline Dictado n. $^{\circ} 11$ \\
\hline Contenidos \\
\hline $\begin{array}{l}\text { Doble } \\
\text { (diferencia fónica entre }\end{array}$ & $\begin{array}{c}\text { acentuación } \\
\text { España y Latinoamérica) }{ }^{13}\end{array}$ \\
- $\begin{array}{l}\text { Uso del guion para separar } \\
\text { sílabas }\end{array}$ & $\begin{array}{l}\text { Tratamiento de las palabras } \\
\text { compuestas } \\
\text { Voseo } \\
\text { ortográfica, gramatical y } \\
\text { cultural) }\end{array}$ \\
\hline Texto & $\begin{array}{l}\text { (componente } \\
\text { El verano antes de tener al bebe, todos los amigos alquilamos un búngalo y } \\
\text { nos fuimos de vacaciones. A unos les gustaba el futbol; a otros, el basquetbol. } \\
\text { Sin embargo, acabábamos todos jugando al beisbol y después con el } \\
\text { búmeran. Cuando salíamos de fiesta teníamos chofer, normalmente Pedro, } \\
\text { por lo que bebíamos coctels y daiquirís a mansalva. Todo quedó registrado } \\
\text { en videos, incluso lo semiilegal. Cuando Pedro se negaba a llevarnos, le } \\
\text { decíamos "Vení y obedecé". La última noche, provocamos un accidente } \\
\text { asustando a un motero que conducía haciendo zigzags. Ese chico nos contó } \\
\text { días después que durante el pre- y postoperatorio solo pensaba en el nené } \\
\text { que estaba esperando junto a su mujer. Él era un gran científico y sabedor de } \\
\text { la estratósfera e hidrósfera, y cuando le pregunté qué era lo último, altivo y } \\
\text { altanero, respondió: "Hi-drós-fe-ra". }\end{array}$ \\
\hline
\end{tabular}

\section{Conclusiones}

Como hemos tenido oportunidad de demostrar a través de sus múltiples variantes, el dictado nos puede ofrecer una amplia gama de explotaciones didácticas y es uno de los ejercicios más productivos para trabajar la ortografía. Esta no ha cosechado buenos resultados en los estudiantes durante la etapa

${ }^{13}$ Sin duda alguna, y si bien se dijo a los estudiantes que debían aguzar el oído, fue el texto más interesante desde el punto de vista didáctico. No se trabajó ningún contenido previo de manera que escribieron las palabras en función de la huella visual que tenían de las mismas y no de la huella acústica. Sin embargo, sirvió para introducir varias actividades repletas de americanismos y la explicación de las palabras que en español pueden tener una doble pronunciación. 


\section{RubÉN GONZÁLEZ VALLEJO}

escolar obligatoria, de ahí los errores cristalizados en la etapa universitaria, lo cual se traduce en la dificultad de aprender la ortografía en la lengua extranjera. Debemos reservar a la ortografía una visión integral que nos permita recurrir a múltiples estrategias con el fin de fomentar en el alumnado la adquisición de normas ortográficas, como por ejemplo a través de la práctica de la escritura y de la lectura o de la traducción, entre otros.

Si bien hemos apuntado diferentes ventajas que producen los dictados en los profesores y en los estudiantes, creemos que son más en estos últimos, pues su aprendizaje autónomo en la autocorrección y la toma de conciencia de su interlengua hace que interactúen directamente con la ortografía. Es por ello que, después de presentar nuestra propuesta de dictados, creemos que se debieran trabajar más en la clase de español, y no solo en ELE, en su justo contexto en todos los niveles; y además ser recogidos en las principales certificaciones de español para extranjeros buscando modelos estándares que no excluyan a los estudiantes cuyos sistemas lingüísticos sean distantes.

\section{Referencias bibliográficas}

Alzugaray Zaragüeta, Pilar; Bartolomé Alonso, María Paz, Preparación al Diploma de Español Nivel C2. Madrid: Edelsa, 2012.

Barómetro Hábitos de Lectura y Compra de Libros en España 2017. Madrid: Conecta, 2018. Disponible en línea en:

http://federacioneditores.org/img/documentos/HabitosLecturaCompraLi bros2017.pdf.

BeníteZ PÉREZ, Pedro, "Dictado y segundas lenguas". En: ASELE, Actas I, 1988, pp. 29-37. Disponible en línea en: https://dialnet.unirioja.es/descarga/articulo/2863649.pdf.

CASSANY, Daniel, "El dictado como tarea comunicativa". En: Tabula Rasa, 2, 2004, pp. 229-250. Disponible en línea en:

https://repositori.upf.edu/bitstream/handle/10230/21268/Cassany_TR_2. pdf?sequence $=1$ \&isAllowed $=\mathrm{y}$.

FERNÁNDEZ-RUFETE NAVARRO, Ana, "Enseñanza de la ortografía, tratamiento didáctico y consideraciones de los docentes de Educación Primaria de la provincia de Almería". En: Investigaciones Sobre Lectura, 4, 2015, pp. 7-24. Disponible en línea en: https://dialnet.unirioja.es/descarga/articulo/5155197.pdf.

FRACA DE BARRERA, Lucía, "El procesamiento psicolingüístico del dictado y sus implicaciones para la enseñanza de la lengua escrita". En: Investigación y Postgrado, 22, 1, 2007, pp. 93-108. Disponible en línea en: https://dialnet.unirioja.es/descarga/articulo/2474597.pdf. 
Ortografía a través de los dictados: propuesta didáctica para italófonos

Hernández Mercedes, María Pilar, "El dictado como instrumento para promover la interculturalidad en el aula ELE: propuestas para el nivel A1". En: Actas del I Encuentro Práctico de Profesores de Español como Lengua Extranjera en la India del Instituto Cervantes de Nueva Delhi, 2011, pp. 67-80. Disponible en línea en:

https://cvc.cervantes.es/ensenanza/biblioteca_ele/publicaciones_centros/ PDF/delhi_2011/12_hernandez.pdf.

MEDiA Guerra, Antonia María, "La enseñanza de la ortografía en la universidad". En: REALE, 2, 1994, pp. 73-78.

MOYA CORRAL, Juan Antonio; GARCÍA WIEDEMANN, Emilio, "El dictado y la comprensión auditiva: un intento de complementariedad". En: ASELE. Actas I, 1988, pp. 203-210. Disponible en línea en:

https://cvc.cervantes.es/ensenanza/biblioteca_ele/asele/pdf/01/01_0351. pdf.

Plan curricular del Instituto Cervantes: Niveles de referencia para el español. Madrid: Instituto Cervantes, 2006.

Pérez Bernal, Rosa María; Quintana Mendoza, Leonor, Preparación al Diploma de Español Nivel C1. Madrid: Edelsa, 2012.

ROLDÁN, Eduardo, ¿Qué es la interlengua? En: Documentos Lingüísticos Literarios, 15, 1989, pp.11-12.

SUAZO PASCUAL, Guillermo, Nueva ortografía práctica: Revisada según las normas de la RAE (1999) y Diccionario de la Lengua Española (22a. ed., 2001) (2a. ed.). Madrid: EDAF, 2005.

VV.AA. Sueña 4. Madrid: Grupo Anaya, S.A., 2008. 